\title{
Cultura escolar e conselho de classe: gestão democrática do trabalho pedagógico?
}

\section{School culture and class council: aspects of the democratic management of the pedagogical work?}

\author{
Beatriz Gomes Nadal ${ }^{*}$
}

\begin{abstract}
Resumo: $\mathrm{O}$ artigo tematiza a cultura do trabalho pedagógico escolar no âmbito do conselho de classe. Muitas pesquisas vêm demonstrando que não raro o conselho atua de modo burocrático e na contramão de um projeto capaz de alinhar as práticas educativas escolares aos interesses sociais. Questionamos quais as formas ritualizadas, os sentidos que envolvem o trabalho pedagógico de conselho de classe e se elas estão associadas à permanência das dificuldades. $O$ trabalho é parte de pesquisa maior, na qual, por meio de abordagem qualitativa com metodologia interpretativa, na perspectiva dos estudos culturais, investigaram-se duas escolas da rede estadual paranaense a fim de conhecer e compreender a cultura escolar, desvelando assim sentidos sobre a avaliação e a gestão do trabalho pedagógico. Para o estudo, apoiamo-nos nas contribuições de Viñao Frago (1998), Dalben (1992, 2004), Mattos (2005) e Oliveira (2002, 2004, 2009). Pudemos perceber que há, nas escolas pesquisadas, um sentido partilhado de avaliação classificatória, do conselho de classe como etapa burocrática, mais do que como um processo inerente ao pedagógico.
\end{abstract}

Palavras-chave: Escola. Gestão do trabalho pedagógico. Conselho de classe. Cultura escolar.

\begin{abstract}
The present article aims to discuss the pedagogical work culture in the scope of the class council. Several studies have shown that often the class council acts in a bureaucratic way and against a project able to align the educational practices of the school with the social interests. Therefore, we seek to question what are the ritualized forms, meanings and beliefs implied in the pedagogical work of the class council and whether or not they are related to the permanence of the difficulties encountered. This work is part of larger research in which, by means of a qualitative approach along with an interpretive methodology, from the perspective of the cultural studies, we have investigated two public schools in the city of Ponta Grossa, State of Paraná, in order to reveal and understand their school culture and, consequently, unveil the methods of evaluation employed and how the pedagogical work was managed. To perform our analysis, we rely on the contributions of Viñao Frago (1998), Dalben (1992, 2004), Mattos (2005) and Oliveira (2002, 2004, 2009). We were able to perceive that in the surveyed schools there is a shared sense of classificatory evaluation, of the school council as a bureaucratic step to be fulfilled, and not as a process inherent to the pedagogical work.
\end{abstract}

Keywords: School. Pedagogical work management. Class council. School culture.

*Professora da Universidade Estadual de Ponta Grossa. E-mail: <beatriznadal@onda.com.br> 


\section{Introdução}

Buscamos, neste artigo, apresentar parte dos resultados de uma pesquisa maior que tematizou a questão da cultura do trabalho pedagógico escolar. Tomamos como pressuposto que, por serem uma construção humana, os processos educativo-pedagógicos da escola expressam não apenas códigos ou normas oficiais, mas também um sistema simbólico sobre o trabalho de educar, atribuindo-lhe sentidos próprios e diferenciados. Existem ideias que circulam e se fazem presentes, convencionando formas de ser, fazer e reagir sentidos e significados que correspondem a uma dada cultura escolar.

A cultura escolar - "teorias, ideias, princípios, normas, pautas, rituales, inércias, hábitos e prácticas (formas de fazer y pensar, mentalidades y comportamientos) sedimentadas a lo largo del tiempo en forma de tradiciones, regularidades y reglas de juego no puestas en entredicho, y compartidas por sus actores, en el seno de las instituciones educativas" (VIÑAO FRAGO, 2002, p. 73) - não está dada nem é definitiva, pois se reconstrói à medida que sofre influência da natureza do trabalho educativo escolar, das necessidades que se impõem à escola, dos constrangimentos vividos, da ação dos sujeitos que dela partilham e sobre ela interferem em função de seus próprios conhecimentos e cultura profissional. A cultura escolar também é influenciada pela estrutura material e organizacional da escola e pela consequente relação mantida com o meio social e o sistema educacional através das políticas e programas educacionais.

Assim, o sistema simbólico escolar atua ora referendando e contribuindo para a continuidade da escola, ora questionando e modificando a realidade dada, pelo que é possível considerar que a cultura possui uma dimensão instituída dada, colocada, estabelecida - e uma dimensão instituinte - em dinâmica e movimento, em reconstrução.

Neste trabalho, que apresenta parte dos resultados de uma tese de doutorado voltada a conhecer e compreender a cultura de escolas públicas de educação básica em seus polos instituído e instituinte, discutiremos sobre os elementos da cultura escolar que se relacionam com o conselho de classe enquanto instância colegiada de gestão do trabalho pedagógico. Visamos contribuir para o desvelamento da cultura de conselho de classe pela compreensão da dinâmica entre os movimentos instituídos e instituintes que a envolvem. A pesquisa foi desenvolvida a partir de abordagem qualitativa com metodologia interpretativa na perspectiva dos estudos culturais.

Segundo Viñao Frago (1998, p. 180), estudar a cultura escolar exige triangular as práticas escolares, a política educacional e as teorias expressadas por 
pesquisadores, pedagogos ou professores. O autor afirma que "Estes [...] aspectos nos conduzirão de cheio [...] a um enfoque que me parece sumamente útil para a análise da cultura escolar: o da confrontação entre a teoria, a legalidade e as práticas ${ }^{1 "}$.

Assim, para estudar a cultura escolar e de conselho de classe, realizamos estudo dos fundamentos legais e políticos da organização do trabalho pedagógico no Paraná, pesquisa de campo com coleta de dados em duas escolas por meio de observação participante e entrevistas, bem como estudo de referencial alusivo à temática, atendendo à triangulação entre políticas, teorias e práticas propostas pelo autor.

A pesquisa em campo, voltada a conhecer as práticas que se travam no interior da escola e captar os sentidos construídos pelos sujeitos - professores e gestores da escola pública de ensino fundamental - foi realizada por aproximadamente 18 meses, em datas alternadas, em duas escolas da rede pública estadual de Ensino Fundamental ( $2^{\circ}$ segmento) do município de Ponta Grossa (as escolas foram designadas como Escola do Vale e Escola da Gema).

Considerando nosso foco nas questões da organização escolar, inicialmente realizamos observação participante em relação ao trabalho de diretores, pedagogos, professores e pessoal administrativo em espaços e momentos coletivos (como a sala de professores ou o conselho de classe, por exemplo). Tais dados foram anotados em diários de campo (D.C.).

Posterior às observações, realizamos entrevistas com professores e gestores, o que permitiu aprofundar, retomar e comparar aspectos, atingindo uma visão mais clara sobre as questões. Com um roteiro estruturado, entrevistamos as equipes de gestão (diretores, vice-diretores e pedagogas) e professores (oito da Escola da Gema e cinco da Escola do Vale).

No que tange à análise documental, examinamos documentos oficiais das escolas - projeto político-pedagógico, livros de registros e fichas/atas de conselho de classe - que julgamos expressar os valores e crenças existentes e a dinâmica impressa ao cotidiano e documentos da política educacional - Plano Estadual de Educação, Caderno de Apoio à Elaboração de Regimentos Escolares, resoluções, decretos e orientações formuladas pela SEED, direcionadas a estruturar o trabalho pedagógico da escola.

O estudo revelou que, apesar de a política educacional/legislação de ensino configurar o conselho de classe como momento democrático fundamental de reflexão sobre a prática educativa, o sentido vigente na cultura escolar é o de uma etapa burocrática a ser cumprida, mais do que o de processo pedagógico emancipatório.

\footnotetext{
${ }^{1}$ Tradução livre.
} 
O artigo está, então, estruturado em quatro partes. Nesta primeira, buscamos situar a temática e a pesquisa. Na segunda, delineamos elementos históricos e políticos que revelam não apenas a institucionalização do conselho de classe, como também as bases políticas em que isso se deu. O terceiro momento traz os dados que permitem conhecer a cultura escolar no que se refere ao conselho de classe. Por fim, são apresentadas as considerações finais do estudo desenvolvido.

\section{A institucionalização do conselho de classe e as políticas educacionais}

Entendemos por trabalho pedagógico o conjunto de atividades educativas realizadas por educadores (docentes e não docentes) visando à concretização de uma dada proposta pedagógica de escola. Contempla programas, projetos, processos e atividades que se desenvolvem numa perspectiva institucional.

O conselho de classe é uma das instâncias colegiadas do trabalho pedagógico, relevante diante de um projeto democrático de escola por representar uma estrutura colegiada capaz de organizar toda a comunidade escolar, de forma participativa, em torno de concepções, objetivos e ações, contribuindo para uma atuação identitária, coerente e corresponsável.

Contudo, a institucionalização dos conselhos de classes e o reconhecimento de seu papel pedagógico não têm sido suficientes para garantir que seus objetivos se efetivem de modo pleno, já que pesquisas feitas sobre o tema vêm demonstrando que muitas vezes eles atuam de modo burocrático e na contramão de um projeto capaz de efetivamente alinhar as práticas educativas escolares aos interesses populares e sociais (DALBEN, 1992; DALBEN, 2010; GUERRA, 2006; MATTOS, 2005; MATTOS; ALMEIDA, 2008; RODRIGUES, 2010; SANTOS, 2006; VARGAS, 2008).

Uma maior compreensão sobre a persistência de práticas contraditórias pode ser atingida se desvelarmos os sentidos culturais que envolvem o conselho de classe, o que exige, por sua vez, que se conheça como ele se configurou historicamente no âmbito das políticas educacionais que o instituíram e o institucionalizaram.

Estudos sobre a história do conselho de classe revelam que sua institucionalização no Brasil se fez no bojo das reformas trazidas pelo Acordo MEC-USAID, em especial o PREMEN - Programa de Expansão e Melhoria do Ensino e a própria Lei 5692/71. Ainda que tais políticas fossem de algum modo vagas em termos de definição acerca de como o conselho de classe deveria se estabelecer, os Conselhos Estaduais de Educação parecem ter traçado linhas norteadoras por meio de resoluções e pareceres, levando a que a sua implantação mais efetiva se desse por meio dos regimentos escolares (DALBEN, 1992, 2010). 
A autora também pontua que ainda que o debate suscitado em 32 pelo Manifesto dos Pioneiros da Escola Nova tenha sido um solo profícuo para que ideias progressistas como a de um colegiado avaliativo se desenvolvessem, não se pode deixar de associar seu surgimento à filosofia de educação que sustentava o projeto educativo daquele momento: uma educação racionalista, tecnicista e voltada à formação de sujeitos que se adequassem à lógica do capital.

Avançando temporalmente, podemos encontrar o conselho de classe já num período de fortes movimentos sociais de luta pela democracia. O fim do governo militar e a abertura política que lhe seguiu inauguraram um novo momento em que as demandas populares no campo político adentram também ao debate da área da educação.

Estudos que trataram da política educacional paranaense (CAVAGNARI, 1998; FIGUEIREDO, 2001; LIMA; VIRIATO, 2007; MARTINS, 1997; NOGUEIRA, 1993; OLIVEIRA, 2004) revelam que desde a década de 80 passou-se a assistir, no estado do Paraná, à defesa retórica da democratização da escola pública. Essa defesa, contudo, não correspondeu a transformações democráticas efetivas.

Dentre outras mudanças, esse novo quadro motivou a institucionalização, no âmbito educacional, dos projetos político-pedagógicos das escolas, dos regimentos escolares próprios e da gestão democrática por meio de instâncias colegiadas como o conselho escolar. Também o conselho de classe foi reconfigurado para que deixasse de ser encarado como instância técnico-decisória e passasse a funcionar como instância colegiada e democrática.

Na prática, a importância dessas iniciativas em face de um processo democrático era ofuscada pelo teor de desconcentração ${ }^{2}$ que efetivamente assumiam, pois toda a concepção e definição de objetivos, formas de trabalho e finalidades era feita na esfera do Estado, cabendo às instituições escolares o papel menor de implementação e prestação de contas, garantindo que no nível institucional se concretizassem os valores do Estado.

É possível inferir, daí, que as políticas educacionais paranaenses desenvolveram-se sob o paradigma de gestão racional-burocrática operacionalizada por movimentos de desconcentração, tendo sido a gestão democrática apenas um mote para encobrir a racionalização e centralidade presentes.

\footnotetext{
${ }^{2}$ Segundo Rivas, citado por Souza (2003, p. 33), a desconcentração é uma modalidade de descentralização. $\mathrm{Na}$ descentralização, as instâncias locais, ao assumirem parte do poder decisório do Estado, contam com real poder de tomada de decisão "sobre aspectos importantes do financiamento, elaboração do currículo local, administração e gestão educacional em áreas geográficas determinadas”, enquanto que na desconcentração o poder decisório continua no Estado, que delega às unidades menores (escolas, por exemplo), a execução de tais diretrizes já definidas.
} 
O caráter desconcentrado das políticas gerou uma grande contradição entre as expectativas existentes no campo social, o discurso de gestão democrática proferido nos textos políticos, as condições efetivamente criadas para a mudança nas relações de participação e a prática efetivada.

Tais políticas implementaram reformas que buscavam mudar a cultura das escolas por meio de artefatos, como o conselho escolar, o projeto político pedagógico e o próprio conselho de classe. Elas atuaram não apenas institucionalizando tais artefatos (sistematizando sua existência em termos de organização), como também buscando instituir novos sentidos para a administração da escola (que inclusive passava a ser tratada como gestão). A tradição de uma direção burocratizada, hierarquizada e centrada no diretor (presente desde o surgimento da escola de massas) deveria ser superada pela gestão com sentidos como democracia, participação, corresponsabilidade e autonomia. Todavia, na lógica da desconcentração, tal intenção instituinte do Estado jamais esteve comprometida com o projeto advindo dos movimentos sociais, mas pretendia, diferentemente, transferir para as escolas e aos educadores parte de suas responsabilidades, numa lógica neoliberal.

O "Caderno de Apoio para Elaboração do Regimento Escolar" (PARANÁ, 2007), elaborado pela SEED na gestão Requião ${ }^{3}$ como proposta para a estruturação do regimento das escolas, pode ser elemento exemplificador de tal análise, já que, ao mesmo tempo em que advogava o princípio de regimentos próprios para cada instituição como expressão de sua autonomia pedagógica, estabeleceu para elas um modelo único previamente definido, que praticamente anulava qualquer possibilidade de diferenciação entre as instituições.

Nesse documento, o conselho de classe foi configurado como uma das instâncias colegiadas de gestão do trabalho pedagógico, possuindo natureza consultiva e deliberativa. Sua finalidade seria a de contribuir para a consecução dos objetivos educacionais por meio da análise e reflexão acerca do processo ensino-aprendizagem e seus resultados.

O conselho de classe deveria estar fundamentado no projeto políticopedagógico da escola e em seu regimento, com foco interveniente e formativo para que fossem construídas propostas e alternativas voltadas ao êxito da aprendizagem e a consecução da proposta pedagógica.

Em termos de sua organização e funcionamento, o Caderno estabeleceu que o conselho de classe deveria ser presidido pelo(s) diretor(res), equipe pedagógica, docentes e alunos que atuassem numa mesma turma e/ou série. Desenvolver-se-ia em dois momentos: um pré-conselho realizado com a participação de toda a classe e sob a coordenação do pedagogo ou professor representante de

${ }^{3}$ Roberto Requião, governador do Estado do Paraná entre os anos 2003/2006 e 2007/2010. 
turma e o conselho de classe integrado, com a participação de diretores, pedagogos, professores e, facultativamente, alunos e pais por turma e/ou série (PARANÁ, 2007).

As reuniões do conselho de classe integrado deveriam ser previstas em calendário, podendo ser realizadas ordinária ou, quando se fizesse necessário, extraordinariamente. Embora a quantidade de reuniões no ano letivo não tivesse sido regulamentada, a SEED prevê no calendário anual que elas sejam quatro, uma ao final de cada bimestre, em dias de sábado.

A importância do conselho de classe foi justificada por seu caráter fundamental enquanto momento de desencadeamento da reflexão sobre a aprendizagem discente, considerando que é durante sua realização que a comunidade escolar deve verificar a relação entre a prática pedagógica da escola e seu projeto político pedagógico, visando estabelecer propostas para correção de rumos e desvios. Outra atribuição do conselho de classe é a decisão responsável sobre a aprovação ou retenção dos alunos (PARANÁ, 2007). Do modo como foi posto, o conselho de classe configurou-se como espaço sistematizado e oficial para a discussão clara e aberta sobre os resultados do trabalho educativo, possibilitando a própria autoavaliação institucional da escola, a definição de necessidades e processos de formação continuada, a reorganização dos planos de trabalho de todos os profissionais e a alteração da organização escolar como um todo.

Todavia, conforme apontamos anteriormente, as contradições são inúmeras, revelando o descompasso entre intenções e ações. Ao mesmo tempo em que o Estado propôs a democratização das relações pedagógicas por meio de um colegiado que analisasse e interferisse positivamente sobre o desempenho escolar, não estabeleceu contrapartidas que garantissem condições materiais para que as decisões da escola contassem com recursos que permitissem sua concretização.

No plano da autonomia pedagógica, também não demonstrou estar propenso a reconhecer e apoiar as decisões que, porventura, fossem tomadas no âmbito do conselho de classe. Por fim, não há como deixar de mencionar que o projeto educativo previsto pelo Estado para o conselho de classe chocava-se constantemente com as pressões - veladas e explícitas - por ele mesmo exercidas para que o conselho funcionasse como instância compensatória dos índices de fracasso escolar, promovendo aprovações em larga escala.

Considerando que os sentidos da cultura escolar decorrem das opções historicamente feitas por determinadas experiências, que passam a ser reproduzidas e mantidas, bem como das pressões sofridas pelos sujeitos no desenvolvimento de seu trabalho, alterando o modo como o percebem, significam e realizam, infere-se que todo esse processo histórico e político influenciou o trabalho pedagógico encontrado no interior das escolas e a cultura a ele correspondente. 


\section{O conselho de classe na complexidade da escola}

Como instância colegiada de gestão, é importante que o conselho de classe tenha a participação não apenas dos docentes, mas também dos pedagogos, diretores, pais e alunos. A participação dos alunos e suas famílias pode se dar de forma direta, com a presença de representantes, ou indireta, por meio do préconselho.

\section{O pré-conselho}

O conselho de classe se inicia com uma etapa prévia a ele, o pré-conselho. No pré-conselho, professores regentes/pedagogos e alunos das diferentes classes devem realizar uma prévia das questões emergentes em relação ao ensinoaprendizagem, levantando elementos voltados a subsidiar a reflexão posterior do conjunto de professores e gestores. Contudo, constatamos que, nas escolas pesquisadas, essa prática não se instituiu plenamente, no período observado.

No início da pesquisa na Escola do Vale (ano 1), o pré-conselho não ocorreu no primeiro bimestre de 2007 e, no segundo, consistiu numa passagem relativamente rápida das pedagogas pelas classes, momento no qual elas questionavam os alunos sobre a visão deles quanto ao rendimento escolar.

Não houve, para aquela ocasião, uma preparação prévia da classe com o professor responsável, o qual também não estava presente quando as pedagogas vieram deliberar com os alunos. Demonstrando não estarem habituados ao procedimento de pré-conselho, eles expressaram uma visão de que tudo corria regularmente e concentraram sua avaliação na questão da disciplina da classe, colocando-se colocaram-se como os responsáveis pelos distúrbios existentes no andamento das aulas:

O problema é a provocação... passam a mão na bunda e colocam apelido. [...]. $\mathrm{Na}$ aula de Geografia todo mundo faz bagunça. [...].

Aluno A: Na aula de História todo mundo fica quieto. [...].

Aluno B: Também, qualquer coisa a professora já diz: "Ocorrência". [...].

A aula que ninguém fica quieto é a de Geografia, que ninguém respeita a professora. [...].

As meninas ficam sem aula e vêm na porta ver o Alisson. [...].

Brincadeiras de mal gosto. [...].

Piás que batem na bunda. [...].

Tem gente que pede pra ir no banheiro e vai namorar. [...].

Os professores se esforçam para ensinar, os alunos não aprendem porque tem bagunça na sala. O conteúdo não é difícil, difícil é ter silêncio para aprender. [...]. (D.C. 03/05/07). 
As considerações feitas pelos alunos trazem elementos relacionais, próprios da juventude, mas ainda assim refletem, em parte, a cultura de "bom aluno" ou "boa aula" que a própria escola inculca, como que a reproduzindo. Charlot (2005) também se refere a esse fenômeno, explicando-o com base na percepção de aula que os alunos possuem; para o autor, os alunos consideram-se sujeitos que devem aprender, e os professores como os que devem ensinar:

Para os alunos de bairros populares, é o professor que cria o saber na cabeça dos alunos, é o professor que tem a atividade no processo de ensino-aprendizagem, não o aluno. O que deve fazer o aluno? Perguntamos para eles: "o que é um bom aluno?" Responderam: "aquele que chega na hora certa na escola e que levanta a mão antes de falar na sala de aula". Não disseram que era o que aprendeu muitas coisas. Ou seja, podem definir um bom aluno sem falar do saber. [...] A causa é a escola. O que a escola francesa ensinou para o aluno? Ensinou que o mais importante é respeitar as regras: chegar na hora certa e levantar a mão. Não ensinou que o mais importante é aprender coisas na escola. (CHARLOT, 2005, p. 68).

O fato é que os alunos terminam por reproduzir o silenciamento que a escola pratica e incute sobre seu trabalho pedagógico. Outro elemento que chamou a atenção foi a organização dada aos dados, que não foram registrados em ficha própria, apenas no caderno de trabalho das pedagogas. Eles também não compuseram a pauta do conselho de classe, o que permite deduzir que o efeito gerado em termos de reflexão sobre o processo ensino-aprendizagem foi praticamente nulo.

$\mathrm{Na}$ Escola da Gema, tal como já indicamos, não acompanhamos nenhum momento de pré-conselho e também não observamos, no desenvolvimento do conselho de classe propriamente dito, que os fatos e eventuais problemas e dificuldades levantados por professores, alunos e pais no decorrer do bimestre tenham sido apresentados, não possibilitando, assim, discussão e confrontação com os resultados apresentados no conselho. A ausência do diálogo com os alunos permite supor a crença de que eles não têm nada a dizer e, assim sendo, não podem participar. Novamente, observou-se na escola uma cultura de participação instrumental e um movimento estratégico, micropolítico.

\section{O conselho de classe integrado}

$\mathrm{Na}$ Escola do Vale, os quatro conselhos de classe propriamente ditos são realizados seguindo o que determina o calendário escolar: normalmente em sábados pela manhã ou então numa noite, sem que haja dispensa das aulas dos turnos diurnos. As pedagogas costumam definir previamente o horário das classes em dois conselhos: um de ensino fundamental $\left(5^{a}\right.$ a $\left.8^{a}\right)$ e outro de ensino médio 
(regular e técnico diurnos). Como há professores que atuam nos dois segmentos e também aqueles que não são docentes de todas as classes, eles se revezam nos dois conselhos, alternando sua presença nas salas.

A Escola da Gema dispensa as aulas para realizar os conselhos de classe nas sextas-feiras que antecedem os sábados previstos no calendário como datas oficiais para esses conselhos. Essa dispensa, embora ilegal (já que subtrai dias dos 200 letivos previstos), não é questionada por nenhum pedagogo ou professor da escola, revelando tradição.

A previsão legal é que os diretores participem da coordenação dos conselhos de classe, mas não é hábito dos diretores e vice-diretores das escolas pesquisadas fazê-lo. A presença deles era aleatória, acompanhando fragmentos do processo, conversando com professores que aguardavam, coordenando o lanche que seria servido ao grupo ou tratando de outros assuntos na secretaria escolar.

Tal conduta dos diretores pode ser reveladora de um entendimento de que o pedagógico é uma questão dos professores e pedagogos e/ou de que o conselho de classe é uma prática burocrática. Também demonstra que a escola cria seu próprio modus operandi, a despeito do que a legislação institui.

Os conselhos de classe seguiam um ritual próprio, para o que eram preparadas fichas específicas; as classes eram tratadas uma a uma, e participavam da reunião os professores que atuavam nas respectivas salas, sob a coordenação das pedagogas.

A condução seguia certa padronização no decorrer do ano; em geral, as modificações referiam-se basicamente à alteração de fichas ou ao responsável por seu preenchimento (houve momentos em que o professor deveria trazer uma ficha previamente preenchida na qual indicava alunos que estavam com nota abaixo da média, alunos com problemas de tarefas ou cujos pais precisavam ser chamados, por exemplo.

O ritual normalmente se iniciava com considerações gerais sobre o trabalho desenvolvido ou sobre os critérios de discussão a serem observados, sem vinculação com as questões da dimensão escolar e docente, tal como pode ser visto por meio dos excertos do diário de campo (D.C.):

A pedagoga inicia falando da sociedade real, competitiva, e da competição positiva. Discute a dificuldade dos alunos, sugerindo de modo claro que a educação dada pelos pais é problemática; cita Tânia Zaguri e seu livro "O professor refém". Solicita aos professores que a entrega de boletins seja um momento "forte" (sugerindo que as questões sejam claramente pontuadas aos pais) e distribui aos professores um artigo da Revista Valor, que recebeu na reunião de pedagogas realizada pelo NRE: "Testes mostram que desempenho de aluno depende mais da família do que da escola". Os comentários aleatórios 
deixam ver a convicção de que, para as equipes pedagógicas e docente, o problema do desempenho dos alunos está na ausência de educação "de base", a qual deveria ser dada pela família. Um professor diz: "A família não está passando valores... eles querem que a escola faça tudo, tudo". A pedagoga assevera aos professores que os alunos de $5^{\text {a }}$ série não entendem suas próprias notas (10 ou 100) e nem mesmo o valor diferenciado de cada atividade; sugere que seja feito um trabalho com gráficos e ressalta: "Os que mais precisam são aqueles que não sabem a nota porque a mãe não vem buscar. Eles pedem 'Ah, professora, me mostre a minha nota, a minha mãe não vem mesmo"'. A professora da classe de apoio fala sobre a fragmentação das disciplinas e a dificuldade das crianças em assimilar o sistema das 5 as séries; os professores não fazem nenhum comentário. (D.C., Vale, 05/05/07).

O conselho inicia com a discussão sobre a recuperação paralela. Os professores reclamam da falta de tempo para realizá-la (para aplicar novos instrumentos de avaliação) e uma das professoras mostra a contradição do calendário escolar, pois o $1^{\circ}$ bimestre teve três meses. Diante da dificuldade da recuperação paralela, uma professora diz: "Eu até conversei com elas (as pedagogas) e fiz diferente, mas o que foi passado pra mim por alguns professores foi que tinha que fazer duas provas". O grupo discute, constatando que não houve padronização de procedimentos pois cada professor organizou o processo de avaliação e recuperação de um modo. Definem, então, que no bimestre toda disciplina deverá ter dois momentos de avaliação e mais duas recuperações paralelas, pelo menos; cada professor decide o peso (não mais $6+4$ ); a paralela será destinada a quem não atingir $60 \%$. O debate deixa transparecer uma concepção burocrática de recuperação paralela, focada na recuperação da nota e não da aprendizagem. Discorrendo sobre a necessidade de que todos os momentos de avaliação sejam registrados no livro de chamada, a pedagoga diz: "Se estiver registrado você está documentado", referindo-se às possíveis reclamações ou recursos legais por parte dos pais. Debatem então sobre o requerimento para alunos que perderam provas, o qual, segundo as pedagogas, tem feito com que os alunos tenham mais responsabilidade. Alguns professores divergem, pois acreditam que, em alguns casos, é melhor negociar a segunda chamada diretamente com o aluno, pois os pais não podem vir à escola preencher o requerimento; debatem se deve ou não haver requerimento para os alunos que perdem a atividade de recuperação paralela e, por fim, decidem que sim. O terceiro ponto da pauta é o momento cívico, que está sendo organizado pelas pedagogas (canto do hino, no pátio, na entrada do recreio); a pedagoga propõe que o professor escolha o aluno e se responsabilize por um tema, mas os professores reagem e não aceitam. Em seguida, a pedagoga avisa que $98 \%$ dos planos anuais estão entregues e relaciona aspectos que foram combinados no início do ano, mas não foram atendidos: passar a data das provas para as pedagogas, informar o horário da hora-atividade, remanejar os horários quando um professor falta e registrar possíveis reposições de aula, retornar rapidamente para sala de aula quando encerra o recreio. A pedagoga 
parabeniza (no geral) os professores que só soltam as classes quando bate o sinal e pede aos demais que façam o mesmo, lembrando que, quando o diretor não está presente na escola, "o pessoal solta antes". Por fim, reafirma o horário de funcionamento da biblioteca, ressaltando que nos dias em que há sala de apoio os professores não devem mandar alunos. "Agora chega de assuntos variados e vamos começar o conselho”, diz. (D. C., Gema, 04/05/07).

Os excertos do diário de campo permitem ver que as escolas administram o escasso tempo do conselho de classe a seu próprio modo quando definem a pauta introdutória. Ainda que o conselho se configure teórica e legalmente como um momento de avaliação sobre o ensino e a aprendizagem, incluindo uma autoavaliação do trabalho pedagógico e didático-pedagógico, percebemos na condução inicial da Escola do Vale uma busca de justificativa, por meio de textos e argumentos, para os possíveis baixos desempenhos a serem posteriormente constatados.

Na Escola da Gema, por sua vez, são tematizados os procedimentos de recuperação paralela (quantidade e valor dos testes aplicados), mas não as possíveis interpretações para os dados de aprendizagem colhidos e a efetividade ou não dos encaminhamentos propostos. Em ambos os casos, os conselhos se apresentam distanciados de uma de suas referências centrais: a dimensão escolar e docente da aprendizagem.

Terminadas as considerações gerais, iniciou-se o tratamento de cada classe em separado. Após a pedagoga anunciar a classe ( $5^{\mathrm{a}} \mathrm{E}$, por exemplo), os professores, aleatoriamente, realizavam comentários sobre o rendimento da turma como um todo e/ou sobre os alunos individualmente; esses comentários se estabeleciam em função dos itens presentes nas fichas de conselho das respectivas escolas, revelando que as instituições desenvolvem uma burocracia ou organização própria.

A Escola do Vale estipulou os quesitos disciplina, rendimento, participação e interesse, comprometimento com tarefas e trabalhos e participação nos projetos da instituição; a avaliação se fez em relação aos níveis excelente, ótimo, bom, regular ou insuficiente. Os professores deveriam indicar, ainda, alunos que haviam se destacado no rendimento escolar, alunos que não demonstraram interesse nas aulas e não participaram com responsabilidade, alunos que demonstraram dificuldades de aprendizagem ou falta de base de conhecimentos. A finalização da ficha do conselho se efetivou por meio da indicação de encaminhamentos a serem feitos pelos professores e equipe pedagógica.

$\mathrm{Na}$ Escola da Gema, a ficha do conselho de classe havia sido organizada em função da relação de alunos, sendo que cada um era analisado frente aos aspectos: indisciplinado, notas abaixo da média, número de faltas, não faz 
atividades, não faz provas e desinteressado. Como na outra escola, o trabalho era concluído com os encaminhamentos necessários.

Novamente vimos reforçada a percepção do conselho como um momento destinado a constatar o desempenho do aluno, do qual se exclui o professor e a organização escolar; o trabalho educativo da escola nem mesmo consta dos quesitos considerados importantes para discussão.

Em ambas as escolas, foi comum que um professor expressasse sua opinião sobre a classe e/ou aluno e que os demais, se concordassem com ele, ficassem em silêncio ou reafirmassem sinteticamente a fala, dizendo, por exemplo: "Comigo também". Quando algum professor discordava da avaliação apresentada pelo colega, a discordância era normalmente apontada: "Na minha não faz", sem que houvesse ponderação sobre os motivos que levavam a diferenças de desempenho. Especialmente nesse momento, em que se debatia sobre a classe como um todo, mas também quando o foco da discussão era o aluno e quando ao final eram levantados os encaminhamentos julgados necessários (diante do desempenho constatado), surgiam as propostas dos educadores:

Prof:: Gente, não tinha que fazer um trabalho com a família? [...].

Prof.: É preciso fazer um trabalho de educação sexual nas quintas séries. [...].

Prof.: Eu sou contra eleição, aluno escolher representante. [...].

Prof:: Eles caíram em produtividade. Nota tem... fazer o quê? [...].

Pedagoga: Vocês devem retomar o mapeamento.

Prof.: Pra você cobrar mapeamento, você perde a aula inteira.

Pedagoga: Mas se todo mundo cobrar, se você cobrar uma aula sim, outra não, eles cumprem. [...].

Prof.: Se a gente conseguisse mais concentração, porque eles são rápidos. (D. C., Vale, 07/07/07).

Encaminhamentos propostos no conselho: passar lista de alunos com dificuldade de aprendizagem para a profa. da sala de recursos, fazer mapeamento da turma, verificar o uso do uniforme, verificar o uso do celular e i-pod (equipe pedagógica), professores exigirem o cumprimento do mapeamento, conscientização sobre o respeito aos colegas e professores e sobre a disciplina, reorganização do sistema de avaliação para alunos que faltam, conversar com a turma sobre os alunos para entrar na $1^{\mathrm{a}}$ aula e na aula depois do recreio, professores falarem a mesma língua, colocando limites e regras, conversar com a turma sobre o incentivo à participação efetiva nos estudos, trabalhar em sala de forma contextualizada, mostrando a aplicabilidade dos conteúdos na vida real. (D. C., Vale, 07/07/07).

Prof:: Precisa fazer algum trabalho com os alunos da $6^{a}$. Sugiro passar nas salas falando da importância de estar na escola, de estar no mundo... alguns alunos estão totalmente sem noção, até por ausência dos pais. [...]. 
Prof.: Esse é o caso de conversar com a família, pelas faltas principalmente. $[\ldots]$.

Pedagoga: Fazer o quê?

Prof.: Trazer o filme do bullyng, trazer, esquecer os conteúdos e fazer um trabalho com eles. [...]. (D. C., Gema, 04/05/07).

Os encaminhamentos apontados pelo conselho foram: orientar para estudos, verificar quem não consegue assimilar, encaminhar para apoio a adolescentes, conversar, motivar, chamar o pai, fazer o termo de compromisso. (D. C., Gema, 04/05/07).

As propostas novamente enfatizavam unilateralmente os alunos e suas famílias, com a necessidade de conversa, orientação e conscientização. Quando se referiam aos professores, possuíam caráter técnico, como não deixar que os alunos trocassem os lugares (mapeamento) ou fazer com que cumprissem as normas escolares. As sugestões dadas às pedagogas possuíam caráter mais formativo, ainda que unilateral (ações da escola para os alunos, mais diretivas do que dialógicas).

À medida que a situação de cada aluno era abordada individualmente, de acordo com a sequência do livro de chamada, os professores teciam comentários sobre eles, conforme os critérios que já indicamos. As observações dos professores eram anotadas pelas pedagogas e, nesse momento, questões familiares ou pessoais dos alunos, quando de conhecimento das pedagogas ou professores, eram socializadas:

Pedagoga: Alessandro.

Prof. A: Que se faz com esse menino?

Pedagoga: O pai quer tirar da escola e pôr pra trabalhar, porque ele já tem 14 anos. A funcionária que trabalha com o pai disse que o menino é excelente. Um menino de 14 anos com os pequenos de $11 \ldots$

A pedagoga conta isso e o conselho continua. (D.C. Vale, 07/07/07).

Prof.: A mãe e o pai estão presos; ele está com um irmão do meio, traficando.

Prof.: Não vem pra aula, fica no boteco jogando sinuca; quando vem, dorme na sala.

Prof: Ela tá muito pior depois do falecimento da irmã no ano passado. Se der oportunidade para tocar no assunto, ela conta nos mínimos detalhes. Depois, o pai traiu a mãe... tudo isso afetou ela. (D.C., Gema, 06/07/07).

Pedagoga: A mãe disse que ele tem renite e não vai mandá-lo para a escola sofrendo, porque ele precisa repousar, que só vai mandá-lo quando ele melhorar. Mas a irmã entregou os pais porque me contou que eles têm seis cachorros e gato; daí ataca a renite do cara. (D.C., Gema, 06/07/07).

Pedagoga: A mãe usa o cartão dele, e ele não pode vir para a escola porque não tem ônibus. (D.C., Gema, 06/07/07). 
Os diálogos travados nos conselhos novamente denotaram a atitude da escola diante da realidade social dos alunos e a ausência de um projeto formativo e emancipatório de médio e longo prazo, voltado ao trabalho com os alunos e suas famílias. Mais do que uma "escola de pais", seria necessária uma abordagem educativa articulada a tal realidade social:

La discusión a darse en el contexto de otro comienzo para niños, niñas y adolescentes es entonces de naturaleza sustantiva y política, y no solo una cuestión de diseño institucional del proceso de enseñanza. Más aún, se trataría de superar la visión economicista del desarrollo educativo, cuya función principal sería aumentar la "empleabilidad" de quienes estudian, por otra en donde la infancia incorpora progresivamente los contenidos que la liberan de un orden opresor. (BUSTELO, 2007, p. 88).

Ao não empreender tal esforço, a escola utilizou a situação dos alunos como justificativa para a não-mobilização do grupo em torno dos problemas de aprendizagem e das possíveis proposições que ela própria necessitaria fazer.

Outro dado relevante é o modo de participação dos professores. Nos momentos iniciais, em que questões pedagógicas eram pontuadas pelas pedagogas, praticamente não se observava contra-argumentação por parte dos professores, que costumavam acompanhar a fala em silêncio, escutando com os olhos baixos, voltados para a mesa ou olhando o "vazio". Poucos professores olhavam as pedagogas nos olhos enquanto elas falavam ou se contrapunham às suas afirmações, a não ser quando o assunto fizesse referência a algum aspecto técnico a ser deliberado, como, por exemplo, a definição de uma data ou de um instrumento de avaliação.

Os professores também consultavam fichas trazidas com os dados dos alunos (na Escola do Vale, algumas vezes elas existiram) e/ou seus livros de chamada; era comum vê-los com a atenção centrada, praticando acertos e realizando preenchimento nos livros, já que a entrega dos canhotos com as notas dos alunos na secretaria da escola representava uma espécie de "missão cumprida" ou encerramento de uma etapa de trabalho, diante do qual outros exerceriam suas responsabilidades, como lançamentos de notas no sistema, produção de boletins, reunião com pais.

A atitude dos professores demonstrava aborrecimento ou exaustão, além de pressa em concluir, pois era possível observá-los desconcentrados, olhando o relógio, com o corpo largado na cadeira, levantando rápido e saindo quando o conselho das turmas em que atuavam era concluído, demonstrando impaciência quando a discussão se fixava num aspecto e não passava para outro item. As expressões faciais normalmente eram de cansaço ou pouco interesse. 
Se participar é envolver-se no coletivo construindo coletivamente sentidos que possibilitem a crítica da situação em que tal grupo está envolvido/ inserido, emancipando-se, consideramos que a postura dos professores revelou compreensão de que são figuras presentes e não sujeitos participantes na condução e decisões do processo. Gohn (2005, p. 31) ressalta que

Para que um indivíduo ou um grupo possa dar sentido à sua participação numa ação social, ele tem que decodificar o significado do que está em tela, em termos do conteúdo das mensagens implícitas, determinar quem é o emissor e o receptador, que universos simbólicos contêm, que valores defendem ou rejeitam. De posse desse acervo de informações, este indivíduo o confronta com seu universo referencial. Essas operações mentais são instantâneas e buscam-se os referenciais na cultura política acumulada por estes personagens, na sua trajetória e experiência de vida; [...] Quando os significados são desvelados, eles produzem estímulos e geram respostas, discursivas ou ações gestuais, ou ações coletivas e movimentos; criam-se processos identitários, individuais e coletivos.

Assim, o modo de estar envolvido no conselho de classe tem permitido a manutenção do ritual vigente, exatamente porque os significados construídos pelos professores em relação a tal momento de avaliação não são trazidos ao nível público e consciente, permanecendo como o extrato da experiência individual de cada professor. Essa tese se comprova pelas falas dos docentes em situação de entrevista, as quais reafirmam seu modo de estar envolvido quando da realização dos conselhos, ou denunciam os sentidos que elaboraram:

O Conselho de Classe é dispendioso. Não há necessidade de você pôr tudo no papel antes e de falar tudo de novo na hora do conselho de classe, ou faz de uma forma ou faz de outra. Eu acho que eu faria o seguinte: uma vez que a gente passa tudo pro papel antes, todas as nossas dificuldades ou não, as coisas boas ou não, notas e faltas, é feito tudo num formulariozinho primeiro, então você já tem uma visão disso, não precisa se falar de novo, eu acho que seria mais aproveitado se: então vamos pegar as situações-problemas e vamos discutir as situações-problemas, tentar resolver de uma forma ou de outra. Como é que pode ser feito isso aqui, como que a gente pode melhorar, como que a gente pode chegar, encontrar esse aluno e cativar e tentar que ele melhore, ver qual é o problema, o que ta ocasionando esse comportamento dessa forma. Eu acho que resolveria melhor, a gente teria, talvez, o mesmo tempo ou até mais trabalhando. Eu acho que nesse caso o trabalho coletivo e uma discussão coletiva talvez chegasse em um acordo, em um consenso. A pasta, às vezes, eu não sei se funciona muito, a gente tem pouco, a nossa equipe é boa mas elas são em poucas pro tamanho da escola e de problemas. Às vezes, ela fica um pouquinho de lado. (Professor 2 - Vale). 
Eu até diria o seguinte: não seria função do Conselho de Classe, eu acho que você não pode resolver um problema no Conselho de Classe porque um Conselho de Classe demora dois meses depois de outro, esses problemas tem que ser resolvidos no dia-a-dia, no cotidiano. O que a gente vê muitas vezes, e isso é uma angústia, é que o problema geralmente vai se enrolando, enrolando, enrolando e você só vê acontecer no final do ano, quando o aluno reprova e daí chega a família e quer saber por quê. E que daí não há mais tempo hábil pra voltar atrás ou corrigir qualquer injustiça. Então o Conselho de Classe até pode auxiliar... (Professor 4 - Vale).

Reunião de Conselho, mas é voltado pra quê? Aluno, não para as, como é que se diz, tudo do professor: se o professor está bem, se o professor está com algum problema em alguma turma, não, é tudo voltado para o aluno. (Prof. 3 - Vale).

Não existe uma discussão com a equipe pedagógica dos problemas porque nos conselhos de classe fala-se somente: esse aluno isso, esse aluno aquilo, esse aluno ta assim e fica por aí, e fica aí mesmo, não buscam, não se busca, eu não vejo, até hoje eu não vi essa busca de solucionar problemas. Vamos então fazer, por quê? Porque o professor coloca o problema, eu coloco o meu problema, o professor coloca o dele e nós ficamos nesses problemas isolados. Então o aluno tem problema e o que se vê então é só queixa, o aluno tem problema. (Prof. 2 - Gema).

Acho que contribui, embora o conselho de classe, muitas vezes, caia naquele problema de estar falando mal do aluno e nem sempre estar apontando soluções. Então, na minha opinião, o conselho de classe seria o momento pra refletir que ações eu fiz pra proporcionar a aprendizagem pro meu aluno. (Prof. 8 - Gema).

E aí nós temos ao final, enquanto sistema de ensino, que no final você tem que aprovar uma quantidade $\mathrm{x}$, daí você faz conselho, daí aprova e vai mandando, manda pra frente. (Prof. 5 - Gema).

Não adianta dizer [as coisas durante o conselho de classe] [...]. Não sei, parece que o conselho, isso parece que está encalacrado até na gente assim, até em mim mesmo, é pra discutir os problemas dos alunos, não da escola, porque a gente acha que o problema da escola são os alunos e quando você dá 5 aulas de manhã, 5 aulas de tarde e não sei quantas à noite, você acha mesmo, e eu não sou hipócrita de dizer pra você assim que não, que tal. (Prof. 3 - Gema).

Reiteramos nossa hipótese de que ao não abrir/forçar espaço para que tais sentidos presentes sejam discutidos e confrontados no grupo, pedagogas e professores revelam uma postura que pode ser interpretada de dois modos: uma possibilidade é a da conveniência de uma participação de caráter administrativo (BALL, 1987), a qual não traz implicações de mudança e permite a continuidade do sistema estabelecido; outra possibilidade é a dificuldade dos professores que 
partilham sentidos similares em se agrupar e gerar, a partir dessa união, um movimento contra-hegemônico instituinte, capaz de estimular o grupo à mudança da situação dada.

Não se pode deixar de destacar que, por certo, o grande número de trabalhos e provas corrigidas pelos professores nos dias que antecediam o conselho foram fatores que contribuíram fortemente para a sua configuração de mais um "protocolo avaliativo" e menos como um espaço democrático participativo, pelo que é possível questionar se não seriam de resistência os movimentos existentes nas escolas:

"Jesus, é muita prova pra pouco professor" - fala de um professor relatando o trabalho para aplicação e correção de provas, correção de trabalhos e preenchimento dos diários de suas 14 classes. (D.C., Vale, 07/07/07).

Cheguei à escola e fui até a sala de professores, onde encontrei alguns atarefados, corrigindo provas e fechando livros. A professora [...] começou a falar; disse que havia ficado até as duas horas da madrugada para fechar uma parte dos livros no domingo, já que na segunda não haveria aula. Para ela, isso não era certo porque seu salário não permite que ela contrate alguém para ajudar nos afazeres domésticos e então ela precisa fazer o trabalho de casa à noite. Além disso, seus filhos precisam de atenção. Ela somou todas as horas que trabalhou em casa fechando notas e livros durante os dias de feriado e concluiu que eram mais de 11 horas. "Essa hora-atividade, eu não precisaria estar aqui”, disse. A professora [...] concordou. Estava tão concentrada acertando as notas e preenchendo os livros que nem mesmo parava para conversar. Contou também que havia feito madrugadas para fechar os livros:"14 livros... sabe o que é isso?", falou. (D. C., Vale, 04/05/07).

Entendemos que a situação do trabalho docente não deve, por outro lado, configurar-se como justificativa definidora de uma situação, mas como um elemento que precisaria estar no centro das próprias reflexões do conselho de classe e da organização escolar, servindo como ponto de partida para a reconfiguração do processo avaliativo, do ensino-aprendizagem, do trabalho pedagógico como um todo e da própria política educacional.

Outra faceta do conselho de classe é a surgida no final do ano letivo, pois no $4^{\circ}$ bimestre letivo o conselho de classe assumiu uma característica particular em relação aos anteriores com um foco central na aprovação ou não dos alunos. Em 2007 as pedagogas da Escola do Vale prepararam uma circular que foi entregue a todos os professores: 


\section{CONSELHO DE CLASSE DO $4^{\circ}$. BIMESTRE}

\section{Caros Professores}

No Conselho de Classe serão analisados os seguintes itens em relação aos alunos:

- rendimento;

- participação;

- aptidão para acompanhar a série seguinte.

\section{NÃO SERÁ DISCUTIDO SOBRE INDISCIPLINA}

\section{Critérios:}

- até 2 disciplinas haverá aprovação automática dos alunos;

- mais de duas disciplinas será feita análise de cada caso dos respectivos alunos. (D.C., Vale, 17/12/07, grifos no original).

Quando o nome do aluno era citado, o professor de cada disciplina dizia, em voz alta, se ele foi aprovado ou reprovado e, em seguida, contavam-se os resultados. Tal como orientava a ficha, o professor que tinha o aluno reprovado apenas na sua disciplina, ao constatar tal situação, já tomava a iniciativa de aprová-lo, registrando em seu livro de chamada a sigla "APC" (Aprovado Por Conselho):

Pedagoga: Reprovado?

Prof.: APC então.

O aluno havia reprovado apenas na disciplina de História; a professora, então, registra a sigla no livro de chamada. [...].

Prof.: Ficou comigo.

Pedagoga: APC então. (D.C. 17/12/07).

$\mathrm{Na}$ Escola da Gema as pedagogas traziam uma ficha previamente preenchida com a maioria das notas finais e, assim, já se tinha uma visão prévia quanto à aprovação ou não dos alunos. Citando o nome de cada aluno já indicavam a situação:

Pedagoga: O Erivelton ficou só em Português.

Prof. A: Então APC.

Prof. B: Ele é bom. (D. C., Gema, 14/12/07).

Assim, nas duas escolas pesquisadas, as discussões se limitaram, no conselho de classe final, a um tratamento com pouca objetividade em relação à situação de aproveitamento dos alunos (sua aprovação ou não); as decisões refletiram ausência de reflexão ou de critérios educativos, obedecendo muito mais à formalização burocrática de "número de disciplinas" do que a indicadores de aprendizagem. Ainda assim, em alguns casos em que a reprovação envolvia alunos já repetentes ou com problemas sociofamiliares mais graves, estabelecia-se alguma discussão: 
Cita-se o nome do aluno, mas antes que os professores iniciem a pedagoga conta que a mãe do aluno veio até a escola, diz que pediu transferência para outra escola e que, sendo assim, solicitou ao Conselho que lembre que ele é limítrofe, que já está saindo da escola e que aprovem para que ele ao menos termine o ensino fundamental.

Prof. A: Ele não merece, esse menino.

Prof. B: Já reprovamos outros que fazem mais que ele.

Uma terceira professora conta que conversou com o aluno (já reprovado duas vezes) e soube que ele trabalha de manhã numa fábrica de móveis e possui um colega de trabalho que agora trabalha também numa churrascaria, recebendo $\mathrm{R} \$ 800,00$ por mês. O aluno disse, então, que não ligaria em reprovar porque quando fizer quinze anos vai ao supletivo e depois pode trabalhar como garçom e receber $\mathrm{R} \$ 800,00$.

Prof. C: Supletivo agora só com 18 anos.

Prof. B: O problema é que ele não é esforçado.

Pedagoga: Então, reprovado. (D.C., Vale, 17/12/07).

$\mathrm{O}$ aluno Evandro já reprovou uma vez a $5^{\mathrm{a}}$ série.

Prof. A: Se nós não aprovarmos, ele vai entrar em depressão... ele chora.

Prof. B: Só que ele não tem condições de acompanhar uma $6^{\mathrm{a}}$ série, nem uma $5^{\mathrm{a}}$.

Prof. C: Ele está em nível de $1^{\mathrm{a}}$ a $4^{\mathrm{a}}$.

Pedagoga 1: Agora já deu pra ver que ano que vem nós vamos ter que pedir apoio pro Núcleo, uma sala de recursos, alguma coisa.

Prof. B: Ele chegou até aqui desse jeito porque todo mundo pensou assim, só que até agora ninguém resolveu o problema dele.

Prof. D: Eu acho que a escola tem que pegar pesado com a mãe dele, porque ela ta deixando muito nas costas da escola. Até na classe de apoio ele deixou de vir porque ela não trouxe mais.

Pedagoga 2: Acho que temos que dar uma documentada e encaminhar pro conselho tutelar.

Prof. A: Eu não sei qual o problema dele e não me sinto em condições de reprovar esse menino assim. Acho que temos que aprovar até como um estímulo pra ele.

Pedagoga 1: Evandro, então, APC. (D.C., Gema, 14/12/07).

Porém, mesmo quando a escola parava para discutir, tal movimento não se fazia com bases que permitiam coerência; o descontentamento com a atitude dos pais, a insatisfação com o comportamento dos alunos e elementos de ordem afetiva como autoestima eram apresentados sem nenhum fundamento que subsidiasse as decisões que tais elementos estavam justificando. A vida do aluno, então, era encaminhada sem parâmetros acadêmicos (desempenho de aprendizagem) ou teóricos (fundamentos para análise). 
Portanto, entendemos que embora não fosse claramente explicitada, a lógica que guiou os conselhos de classe durante o ano e no momento decisório sobre aprovação foi a do esforço empreendido pelo aluno (realiza ou não atividades durante as aulas, entrega trabalhos e tarefas), mais do que a da aprendizagem (aprendeu ou não o conteúdo):

Prof:: Na verdade a Paloma não gosta de estudar, mas ela está fazendo um esforço. [...].

Prof.: Franciele falta nas provas. [...].

Prof:: A gente percebe que ela é dedicada. [...].

Prof:: O problema é o tratamento com os colegas; ele usa termos chulos e graves. [...].

Prof.: Suellen tá largadinha... a mãe tá presa, o pai não sei o quê. [...].

Prof:: Tem cheirinho de falta de banho. [...].

Prof.: Faltoso. [...].

Prof.: Não faz as atividades. Você fala com ela, ela faz de conta que tá fazendo, quando você chega perto, não tá fazendo nada. [...]. (D. C., Vale, 07).

Prof.: Bernadete é muito limitada... ela até tem vontade, mas não consegue. [...].

Prof.: Tem uma certa limitação, mas tem boa vontade. [...].

Prof.: É inteligente, mas não quer saber de nada. [...].

Prof.: Faz tudo, ela é boa. [...].

Prof:: Fraquíssimo, desinteressado, não faz as atividades e ele sempre diz que não é obrigado. [...].

Prof:: O problema maior é o desinteresse, sem ânimo, sem motivação. [...].

Prof:: Vai bem, participa, faz as atividades. [...].

Prof.: Esforçada... faz tudo errado, mas faz. [...].

Prof.: Dissimulado, quando ele quer, ele faz. [...]. (D. C., Gema, 07).

Esforço, vontade, frequência, interesse, realização do prescrito, postura, dedicação, responsabilidade pesaram mais nas decisões docentes do que a aprendizagem desenvolvida, a qual, novamente ressaltamos, raramente era confrontada ou tematizada ao lado do trabalho docente e da organização escolar existentes. Interessante é confirmar que, ao mesmo tempo em que a escola se apegava à questão da nota, muitas vezes utilizando-a como pretexto para a inflexibilidade avaliativa, ela não hesitava em quebrar tal regra quando considerava o "merecimento" dos estudantes. Assim, vemos que o conselho de classe não deliberava em torno de um claro processo dialógico e que há ausência de dados objetivos (objetivos atingidos, conteúdos dominados, desempenhos desenvolvidos) relacionados às questões de ensino-aprendizagem tratadas:

Prof:: Esse menino merece passar, porque teve um crescimento muito grande. [...]. Pedagoga: Darlan? 
Professores, em coro: Reprovado.

Prof. A: Com louvor.

Prof. B, em tom de riso: Você vai pro inferno. [...]. (D.C., Vale, 17/12/07).

Leem o nome de uma aluna e seu número de faltas: “45, 41, 29, 18 ... 225 faltas e ainda falta computar duas disciplinas". A pedagoga diz que, em princípio, está reprovada por faltas e que verificará na secretaria se a aluna trouxe atestados médicos.

Profa. Apoio: Vocês querem uma opinião? Tem que ser falado com a mãe dessa menina, ela tem que saber essa questão das faltas.

Prof. X: Mas então, se é tanto assim, que fique reprovada por falta.

Prof. Apoio: Tem que reprovar essa menina porque ela é uma safada. Ontem eu falei com a psicóloga - porque nós estávamos fazendo um trabalho conjunto - e a mãe contou pra ela que já falou com todos os professores e ela está aprovada. [...].

Prof. C: Olhe, o Evandro só brincou. Se ele passar agora, não vai fazer nada na $8^{\mathrm{a}}$.

Prof. D: É o caso de reprovar igual fizemos com outros alunos.

O aluno é reprovado mas a professora sentada ao meu lado mostra-se descontente. Ela se aproxima de mim e fala de modo cochichado:

Prof. E: Só que o Evandro, ele é inteligente, isso que me dá dó. Ele pega uma prova de matemática, ele detona.

Pergunto, então, porque ele não tem nota e a professora responde que é porque não faz os trabalhos e porque bagunça em sala. (D.C, Vale, 17/12/07).

Prof.: Aluno que não vem na minha aula e faz, eu até passo, mas aluno que não faz nada, eu não passo. [...].

Prof.A: Pode ser APC, porque tem 55 de média. [...].

Prof.B: Comigo também.

Pedagoga: APC, então.

Prof. A: Tem que cuidar das faltas dele no ano que vem. [...].

Vice-Diretor: Vocês que tem que dizer, porque nós não estamos com eles todo dia.

Pedagoga: Ele tem condição de acompanhar a $6^{a}$ série?

Prof. E: Acredito que sim... Mas acho que a Natali também acompanharia...

Prof. F: Ficou reprovada por comportamento...

Prof. G: Mas ela não faz!!! (exclamando).

Pedagoga: Ficou reprovada em 5 matérias, já é a segunda reprovação.

Prof. E: Ela não quer nada com nada... [...].

Prof.: Dá um dozinho... eu gosto do João Fernando... [...].

Prof.: Esse, pode falar que ele tem problema porque eu não quero nem saber. Vadio, sem vergonha, não copia. Eu reprovo. [...]. (D. C., Gema, 14/12/07). 
O quadro descrito permite questionar em que medida os professores realmente compreendem o sentido do conselho de classe no processo de avaliação e denota que os esforços instituintes advindos da política educacional (por meio de resoluções, regimentos e da teorização a eles subjacente) são frágeis diante das concepções e, consequentemente, da má formação dos professores e gestores. Nossa análise confirma, por sua vez, a já estabelecida por Mattos (2005, p. 227), quando afirma:

A observação dos Conselhos confirma ainda a hipótese de que a interação pedagógica jamais é levada em conta, seja pelas próprias professoras, seja pela instituição escolar. Não existe no seio desta última nenhuma instância de reflexão crítica sobre a prática das professoras. [...] Desta maneira, a análise desses Conselhos alerta para o fato de, com freqüência, esses alunos e alunas se tornarem vítimas do despreparo dos professores em lidar com a complexidade da situação pedagógica. Ao contexto da violência simbólica (Bourdieu, 1970) inerente ao exercício da profissão de professora, alia-se à violência da discriminação social, da imprecisão conceitual quanto às causas do fracasso escolar e até mesmo da agressão verbal na descrição de alunos e alunas.

Por mais que a escola e os professores conduzam o conselho de classe a seu próprio modo, eles ainda acreditam que o NRE/SEED exerce pressão sobre eles para que as reprovações sejam evitadas. Para os educadores, mecanismos trazidos ao longo dos últimos anos pelas políticas educacionais voltados à correção dos fluxos escolares - programas de correção idade x série, aprovação com dependência desde a $5^{\text {a }}$ série, fechamento de classes de ensino regular noturno e estímulo à realização de estudos na modalidade "jovens e adultos" (EJA), pressão dos diretores pela melhoria das estatísticas escolares, diminuição da média para aprovação - foram os grandes responsáveis pelo atual desestímulo dos alunos por gerarem uma espécie de cultura de aprovação sem estudo ${ }^{4}$.

Segundo os professores, os alunos ainda acreditariam que todos, indistintamente, seriam aprovados e, por isso, eles (professores) viam na reprovação um mecanismo de alerta e chamada de atenção, um sinal de que é preciso estudar, pois as aprovações não seriam dadas gratuitamente:

Prof.: Essas sétimas têm muito aluno nosso que foi reprovado ano passado, por isso que elas estão boas. [...]. (D.C. Vale,17/12/07).

Olha, o Evandro só brincou. Se ele passar agora, não vai fazer nada na $8^{\text {a }}$. (D.C. Vale,17/12/07).

Pedagoga: APC pro Bruno? Damos uma chance?

\footnotetext{
${ }^{4}$ Veja-se mais em: LIMA, A. B. de; VIRIATO, E. O. A gestão da educação e as políticas educacionais no Estado do Paraná. São Paulo, Cadernos de Pós-Graduação (UNINOV), v. 6, p. 181-189, 2007.

OLIVEIRA, D. A. Estudo dos conflitos nos sistemas educacionais da região: agendas, atores, evolução, manejo e desenlaces - relatório de estudo de caso do Brasil. Rio de Janeiro: LPP; Buenos Aires: OREALC/ UNESCO, 2004.
} 
Prof.: Ele vai sentir essa reprovação e vai mudar? [...].

Prof.: Eu acho que se a gente segurasse ele, dava uma espertada. [...].(D. C. Gema, 14/12/07).

Prof.: Nossa, como a Kerolyn melhorou. A reprovação fez bem pra ela. [...]. (D. C. Gema, 14/12/07).

Prof. A: Tiago precisa ir, é muito passadinho. (D. C., Gema, 19/10/06).

Prof. B: Também, é aluno de aceleração. [...]. (D. C., Gema, 19/10/06).

A crença na avaliação como instrumento disciplinador é bastante forte e ainda que se fizesse presente de modo corrente, ela não foi tomada como objeto de reflexão.

\section{A cultura do conselho de classe}

A escola é uma forma cultural, uma instituição que desenvolve um trabalho essencialmente humano, de pessoas para com outras pessoas, de pessoas formando e contribuindo para a humanização de pessoas. Expressa sentidos históricos próprios sobre seu trabalho pedagógico; sentidos que ora mantém, ora reconstrói, ora altera. Seu trabalho pedagógico, além de pautar-se em condições organizacionais e materiais e em diretrizes políticas, sustenta-se também na cultura escolar que a própria escola gera e transmite.

No campo das teorias pedagógicas, o conselho de classe é configurado como instância avaliativa de natureza colegiada, instituída para que gestores, docentes, alunos e/ou famílias trabalhem coletivamente em torno dos resultados do processo ensino-aprendizagem, contribuindo para a democratização das práticas educativas por aproximar concepções, percepções e posicionamentos dos diferentes sujeitos (em especial dos alunos e suas famílias). Permite descortinar dificuldades e contradições e desenvolver uma visão mais abrangente, articulada e objetiva da realidade, com tomada reflexiva de decisões.

Observando como, por sua vez, algumas políticas educacionais trataram e tratam o tema, vemos que tais discursos oficiais surgem historicamente concebendo o conselho de classe como uma ferramenta para o alcance do êxito educacional numa perspectiva centralizadora. Eles avançam encampando o discurso acadêmico e passando a afirmar o caráter democrático e formativo que o conselho de classe precisaria assumir. Todavia, permanece a concepção que atrela a educação aos interesses do capital, incluindo aí a desresponsabilização do Estado, pelo que se constata um desvio semântico que usa a ambiguidade de significados para produzir textos legais que retratam elementos de um projeto político democrático, porém com intenções de significado pertencentes a um projeto neoliberal ${ }^{5}$.

\footnotetext{
${ }^{5}$ A esse respeito ver o trabalho de Drabrach e Mousqueur (2009).
} 
Esses sentidos, social e politicamente construídos, inevitavelmente impactaram o trabalho pedagógico da escola à medida que trouxeram pressões de ordem simbólica acerca do que se espera que seja feito, como também de ordem prática, quando introduziram novas e complexas demandas de trabalho sem contrapartidas para a estrutura organizacional das escolas e para as condições de trabalho docente.

Todavia, ao adentrarmos no universo escolar, percebemos que as escolas não se submetem de forma plena àquilo que a legalidade institucionalizou. Suas atribuições mais relevantes - a análise dos dados quantitativos e qualitativos apurados pelo processo de avaliação da aprendizagem, a proposição de outros encaminhamentos metodológicos e o estabelecimento de mecanismos de recuperação da aprendizagem - foram praticamente deixadas à margem na medida em que eram tomadas decisões bastante restritas a elementos organizacionais, como mudanças de lugar nas classes, ou ao trabalho discente, tomado unilateralmente.

Apesar de a política educacional/legislação de ensino configurar o conselho de classe como momento relevante de reflexão sobre a prática educativa, o sentido vigente nas escolas pareceu perpetuar aquele historicamente construído, etapa técnico-burocrática necessária à organização do trabalho, de componente que precisa ser cumprido, mais do que processo inerente ao pedagógico, num movimento que se distanciava da perspectiva democrática.

Os encaminhamentos dados ao conselho de classe revelaram que, na escola, a avaliação ainda segue uma tradição classificatória que a posiciona apenas em relação à aprendizagem, e não ao ensino, o que justificaria focalizar tal aprendizagem dentro de elementos socioeconômicos e culturais, e não pedagógicos.

Também se percebeu que, na prática, as escolas exerceram forte poder decisório sobre a aprovação ou reprovação dos alunos e que realizavam tal deliberação a partir de critérios próprios, ainda que a ideia da diminuição dos índices de reprovação estivesse fortemente presente na escola - mesmo que não fosse explicitamente dita, mas que se revelava de modo implícito nos estudos pedagógicos da formação continuada, na preocupação de diretores e pedagogos, no constrangimento sofrido por aquele que retinha grande número de alunos - e de a escola afirmar não ter poderes sobre a retenção dos alunos, haja vista a pressão do sistema educativo para que o maior número de alunos fosse aprovado.

É importante perceber que, por fim, no que se refere ao conselho de classe, a cultura das escolas ainda está próxima dos sentidos autoritários e centralizadores historicamente construídos, que configuraram como técnico o trabalho feito nessa instância colegiada e como classificatória a avaliação aí praticada.

O Estado buscou, sem êxito, alterar tais sentidos, inicialmente construídos, por outros que levassem a escola a responsabilizar-se, quase que sozinha, 
pelos resultados educacionais. A escola resiste sem, contudo, contrapor um projeto democrático próprio.

\section{Referências}

BALL, S. J. La micropolitica de la escuela: hacia una teoría de la organización escolar. Madrid: Paidós Ibérica, Centro de Publicaciones del M.E.C. 1987.

BUSTELO, E. S. El recreo de la infancia: argumentos para otro comienzo. Buenos Aires: Siglo XXI, 2007.

CAVAGNARI, L. B. O projeto político-pedagógico e a autonomia da escola: limites e possibilidades (a experiência do sistema estadual de educação do Paraná). 1998. 317 f. Dissertação (Mestrado em Educação) - Universidade Estadual de Ponta Grossa, Ponta Grossa, 1998.

CHARLOT, B. Relação com o saber, formação dos professores e globalização: questões para a educação de hoje. Porto Alegre: Artmed, 2005.

DALBEN, A. I. L. F. Conselho de classe. In: OLIVEIRA, D. A.; DUARTE, A. M. C.; VIEIRA, L. M. F. Dicionário: trabalho, profissão e condição docente. Belo Horizonte: UFMG/Faculdade de Educação, 2010. CD-ROM.

DALBEN, A. I. L. F. Conselho de classe e avaliação: perspectivas na gestão pedagógica da escola. Campinas: Papirus, 2004.

DALBEN, A. I. L. de F. Trabalho escolar e conselho de classe. Campinas: Papirus, 1992.

DABRACH, N. P.; MOUSQUER, M. E. L. Dos primeiros escritos sobre administração escolar no Brasil aos escritos sobre gestão escolar: mudanças e continuidades. Porto Alegre: Currículo sem fronteiras, v. 9, n. 2, p. 258-285, jul./dez. 2009.

FIGUEIREDO, I. M. Z. Políticas educacionais para o estado do Paraná nas décadas de 80 e 90: da prioridade à "centralidade da educação básica". 2001. 179 f. Dissertação (Mestrado em Educação) - Faculdade de Educação, Universidade Estadual de Campinas, Campinas, 2001.

GOHN, M. G. M. Movimentos sociais e educação. São Paulo: Cortez, 2005.

GUERRA, M. G. G. Conselho de classe: que espaço é esse? 2006, 205 f. Dissertação (Mestrado em Linguística Aplicada e Estudos da Linguagem) - Pontifícia Universidade Católica de São Paulo, São Paulo, 2006.

LIMA, A. B. de; VIRIATO, E. O. A gestão da educação e as políticas educacionais no Estado do Paraná. Cadernos de Pós-Graduação (UNINOVE), São Paulo, v. 6, p. 181-190, 2007.

MARTINS, R. B. Escola cidadã do Paraná: análise de seus avanços e retrocessos. 1997. 214 f. Tese (Doutorado em Educação) - Universidade Estadual de Campinas, Campinas, 1997.

MATTOS, C. L. G. O conselho de classe e a construção do fracasso escolar. Educação e Pesquisa, São Paulo, v. 31, n. 2, p. 215-228, maio/ago. 2005. DOI: 10.1590/S151797022005000200005 
MATTOOS, C. L. G.; ALMEIDA, S. M. O conselho de classe como articulador de uma orquestração marginalizadora do aluno. 2008. Disponível em: <http://www. educacaoonline.pro.br>. Acesso em: 26 jan. 2008.

NOGUEIRA, F. M. G. Políticas educacionais do Paraná: uma versão institucional da proposta pedagógica dos anos oitenta. 1993. 102 f. Dissertação (Mestrado em Educação) Pontifícia Universidade Católica de São Paulo, São Paulo, 1993.

OLIVEIRA, D. A. Estudo dos conflitos nos sistemas educacionais da região: agendas, atores, evolução, manejo e desenlaces - relatório de estudo de caso do Brasil. Rio de Janeiro: LPP; Buenos Aires: OREALC/UNESCO, 2004.

OLIVEIRA. D. A. (Org.). Política e gestão da educação. Belo Horizonte: Autêntica Editora, 2002.

Regulação e avaliação de políticas públicas educacionais. In: DOURADO, L. F. (Org.). Políticas e gestão da educação no Brasil: novos marcos regulatórios? São Paulo: Xamã, 2009. p. 15-29.

PARANÁ. Secretaria de Estado da Educação. Caderno de apoio para elaboração do regimento escolar. Curitiba, 2007. Disponível em: <http://www.diaadiaeducacao.pr.gov. br/diaadia/diadia/arquivos/File/escola/Regimento\%20Escolar.pdf $>$. Acesso em: 25 set. 2007.

RODRIGUES, I. C. Os ciclos e os conselhos de classe: o êxito e o fracasso escolar (ainda) em questão. 2010. 183 f. Dissertação (Mestrado em Educação) - Faculdade de Educação, Universidade de São Paulo, São Paulo, 2010.

SANTOS, F. R. V. dos S. Conselho de classe: a construção de um espaço de avaliação coletiva. 2006. 137 f. Dissertação (Mestrado em Educação) - Faculdade de Educação, Universidade de Brasília, Brasília, 2006.

SOUZA, A. R. A escola por dentro e por fora: a cultura da escola e a descentralização financeira, Revista Iberoamericana de Educación, Espanha, v. 10, p. 1-14, 2003. Disponível em: <http://www.rieoei.org/deloslectores/516Souza.PDF>. Acesso em: 12 nov. 2005.

VARGAS, M. A. S. O conselho de classe: a participação da comunidade escolar. 2008. 134 f. Dissertação (Mestrado em Instituição Educacional) - Universidade do Oeste Paulista, Presidente Prudente, 2008.

VIÑAO FRAGO, A. Historia de la educación y historia cultural: posibilidades, problemas, cuestiones. Revista Brasileira de Educação, Rio de Janeiro, p. 63-82, set./dez. 1995.

Por una historia de la cultura escolar: enfoques, cuestiones, fuentes. In: FERNANDES, C. A. et al. Cultura y civilizaciones. III Congreso de la Asociación de Historia Contemporánea. Valladolid: Secretariado de Publicaciones y Intercambio Científico, Universidad de Valladolid, 1998. p. 167-183.

Sistemas educativos, culturas escolares y reformas. Madrid: Morata, 2002.

Recebido em 27/01/2012

Versão final recebida em 02/05/2012

Aceito em 03/05/2012 